\title{
DYNAMIC MANAGERIAL CAPABILITIES AS ANTECEDENT OF CORPORATE ENTREPRENEURSHIP: A CONCEPTUAL MODEL
}

\author{
Ntandoyenkosi Sibindi' Orcid ID: orcid.org/0000-0002-6560-5743
}

\begin{abstract}
:
Current studies on Corporate Entrepreneurship (CE) present organisational boundaries, discretionary time, rewards/reinforcements, work discretion and management support as antecedents of CE. This ignores the fact that all these variables are a managerial function in organisations. Furthermore, considering these variables at the same predictor level as management support, has contributed to entrepreneurship coordination challenges for organisations. To address this predicament through the lens of dynamic capabilities, we submit a conceptual model that considers dynamic managerial capabilities as antecedents of CE.
\end{abstract}

Keywords: Organisational Capabilities, Dynamic Managerial Capabilities, Corporate Entrepreneurship

\section{Introduction}

The survival, growth and profitability of an organisation are largely dependent on its entrepreneurial mindset and behaviour (Hisrich and Peters, 1992). The term Corporate Entrepreneurship (CE) according to Dhilwayo (2010), is a mindset that resides in the set of activities and attitudes that enables the organisation to pursue new opportunities, create new business units, new products, and shape corporate strategy renewal. The dynamic business environment accelerated by the demands of the Fourth Industrial Revolution, has increased operational risk and opened up new opportunities for organisations. CE is pivotal in enabling organisations to mitigate the uncertainty and harness the opportunities (Morris, Kuratko and Covin, 2011). The process of building entrepreneurial organisations has received scholarly attention in the last decade. Core to this process are organisational boundaries, discretionary time, rewards/reinforcements, work discretion and management support, organisational culture and structure (Hornsby, Kuratko, Holt and Wales (2013). These variables contribute to the ecosystem of CE and have a managerial function. This postulates that CE has to be stimulated, nurtured and managed, making dynamic managerial capabilities an antecedent of CE.

Drawn from the resource-based view of a firm (Bowman and Ambrosini, 2003), evolutionary economics (Winter, 2005) and strategic management (Agarwal and Selen,2009), dynamic capabilities of which dynamic managerial capabilities are part of, are routine-based (Winter, 2013), knowledge-based (Kogut and Zander,1992) and resourcesbased (Bowman and Ambrosini, 2003). Dynamic capabilities assist organisations to innovate their systems and restructure themselves in the ever-changing environments (Gottschalg and Zollo,2007). Diverse dynamic capabilities emerge from literature: marketing, innovation, and management (Winter, 2003).

The paper considers dynamic managerial capabilities as a predictor of organisational entrepreneurship. Managerial capabilities coordinate organisational skills and environmental change (Helfat \& Martin, 2015). Managers nurture, maintain and direct the entrepreneurial processes. They coordinate and foster cohesion between human and non-

${ }^{1}$ University of the Western Cape, School of Business and Finance 
human resources for the survival and growth of the organisational (Andersson, and Evers,2015). This puts dynamic managerial capabilities at the centre of an organisation's entrepreneurial ecosystem. Despite these fundamental roles that managerial capabilities play in the creation and maintenance of $C E$, the concept has escaped scholarly attention, hence, the aim of this work is to develop a theoretical model that accounts for managerial capabilities as an antecedent of CE.

To premise the theoretical model, the paper discusses prevailing thoughts on dynamic capabilities in general and dynamic managerial capabilities in particular. The paper also reviews the concept of CE, prior to presenting the model. We conclude by highlighting theoretical contributions, indicating implications to practice, potential limitations as well as suggestions for further research.

\section{Conceptualisation of Organisational Capabilities}

The propensity to innovate and survive the ever-changing business environment, compelled firms at the turn of the millennium to expand their organisational capabilities. Honed by globalisation, new technology, shift from labour to capital intensity, and the general complexity ushered in by the Fourth Industrial Revolution, organisational capabilities have assisted firms to weather competition and push for growth. The genesis of the organisational capabilities can be traced to pre-World War 1 when American and German firms used it to challenge British competitors in international and domestic markets (Chandler, 1977). In his chronicle of the history of enterprises, Chandler (1991) credits Organisational Capabilities for enabling the Japanese firms to carry out a massive transfer of technology from the West to Japan - a scenario that gave rise to large enterprises in Japan.

Drawn from the resource-based view of a firm, and championed by the evolutionary theorist of a firm, Winter (1987) and Nelson \& Winter (2009) state that organisational capabilities are routine-based, but distinguish themselves from routines by being "high level routine or a collection of routines" (Winter, 2000p, 981). A routine is a learned behaviour by an organisation that manifests itself in organisational culture (Winter, 2000). Organisational capabilities allow managers to supplement the three traditional means of achieving competitive advantage (finance, strategy and technology).

By nature, organisational capabilities are a process-oriented concept that includes all organisational activities and changes as the business-operating environment changes (Schienstock, 2009). They understand change as a continued and open-ended process of organisational development, hence they "confer on management a set of decision options for producing significant options outputs of a particular type (Winter, 2000, p. 292). Through organisational capabilities managers are able to organise and deploy resources through processes. The human agency coordinates other resources, thus placing human capital development at the epicentre of the capabilities process (Ulrich and Lake, 1991). For the human agency to perform this task, a knowledge base is very important. The acquisition of knowledge is a function of experience and training. This is the knowledge-based view of capabilities that is held by Zollo and Winter (2002), Ambrosini, Bowman and Collier (2009).

How firms can develop organisational capabilities has become a subject of inquiry in both management and organisational circles. Two views on how organisational capabilities are created are evident in capabilities scholarship. The emergent-by-nature view is held by the traditional institutional sociologist (Selznick,1957) and the evolutionary economists, Winter (2003), Eisenhardt \& Martin (2000) and Nelson \& Winter (2009). Core to this view is the fact that organisational capabilities emerge naturally, as the organisation interacts with its environment (Nelson and Winter, 2009). On the other hand, the contemporary view attributes organisational capabilities to managers' intentions, as they perform their managerial roles (Ambrosini and Bowman, 2009). Micro and macro level studies of organisational routines by Gavetti (2005) confirm both views.

Two types of organisational capabilities are prominent in literature, and are essential and are also referred to as operational (Winter, 2000, Liu, Grant, McKinnon and Feng, 2010) and dynamic capabilities (Winter, 2003, Helfat and Peteraf, 2003, Coad, 2009, Dosi and Nelson, 2010, Felin, Foss Heimeriks and Madsen, 2012). Core capabilities drawn from the history of enterprises presented by Chandler $(1992$, p.86) are "a hierarchy of practiced organisational routines, which define lower order skills required at the lower levels of the hierarchy". Conceptualised from this definition, core capabilities form the foundation of organisational operations. Chandler (1992) concludes that core capabilities are the platform on which organisations build confidence for their operations. Ambrosini \& Bowman (2009) suggest the following as characteristics of core capabilities: human capital skills, physical systems, managerial systems and organisational models. When all these elements are combined and processed, they form core capabilities. 
Dynamic capabilities are activities that enable organisations to adjust to endogenous changes that occur daily in their operations (Ambrosini, Bowman and Collier, 2009). This assigns dynamic capabilities to the task of reconfiguring core capabilities, as they interface between the organisation and the environment. From a strategic view, dynamic capabilities are the firm's endeavours to differentiate itself from its competitors by pursuing a peculiar behaviour that is difficult for competitors to imitate (Agarwal and Selen,2009). Dynamic capabilities are regenerative in nature. They allow organisations to reconfigure their resources, position and strategy (Bowman and Ambrosin, 2003), and to leverage their resources (Pavlou and El Sawy, 2011). Dynamic capabilities allow the organisation to learn through adaptation and creation of new capabilities (Zollo and Winter, 2002). Through sensing and seizing, dynamic capabilities allow firms to position themselves favourably in an environment, and to explore the new opportunities that arise (Danneels, 2012). Furthermore, these capabilities allow knowledge creation and integration (Ambrosini, et. Al, 2009).

A series of dynamic capabilities emerge from literature. Among them are the dynamic technological capabilities, dynamic marketing capabilities, and dynamic managerial capabilities (Correa, Bueno \& Kato, 2017). Of interest to our presentation is the dynamic managerial capability. Conceptualised as the role of human agency in the capabilities formation, dynamic managerial capabilities are responsible for resources allocation, coordination, combination, control and providing a general nexus with organisational entrepreneurship, hence, they become imperative to consider dynamic managerial capabilities as predictor variables in the stimulation, nurturing, coordinating, and maintenance of the organisational entrepreneurship process.

\section{Conceptualisation of Dynamic Managerial Capabilities}

Drawing from the role of human agency, Rosenbloom (2000) tinted the importance of managerial input in the dynamic capabilities process (Rosenbloom,2000). This notion was refined, transformed and consolidated by Adner and Helfat (2003), who referred to dynamic managerial capabilities as those capabilities that enable managers to acquire, coordinate, combine, allocate, configure and reconfigure resources. To calibrate the resources into dynamic capabilities, managerial capabilities are guided by three underlying factors: human capital, social capital, and managerial cognition (Adner \& Helfat, 2003; Helfat \& Martin, 2015). These individual components or a combination thereof, enable managers to navigate the complex business environment that adjust to market changes. It was also discovered that they influenced managerial operational or strategic decisions (Helfat \& Martin, 2015).

According to Castanias and Helfat (1991), managerial human capital is a combined function of the skills, expertise, and knowledge on how to orchestrate human resources in an organisation that managers acquire over time (from talent, acquisition to development). Simon and Hitt (2009) concluded that human capital management through talent pooling, development and teaming, resulted in increased performance by firms. Through effective management of human capital, talent synergies are established (Wright, Loff and Moliterno, 2014). These talent synergies form a strong basis for dealing with environmental changes, navigating new markets, and creating new products and customers. Organisational and management literature is awash with evidence that teamwork is a result of effective human capital management, and its positive impact on organisational development is known (Robbins, 2003).

Social capital is the value related to social connections within a firm (Burt,2005). The human relations theorist promulgated the importance of social security in the motivation matrix (Maslow, 1963). Beyond motivation, social capital finds the relationship among individuals a source of capital for the firm (Putman, 2000). Social capital is the sanctuary of building trust and collaboration and a goodwill among managers and the human resources in a firm. Such an environment is closely linked to the development and nurturing of CE (Morris and Kuratko,2002). Through social capital, managers secure and configure resources (ler \& Coff, 2003). Being better connected, adds to managers' efficiency and effectiveness by providing a thoroughfare from different sources to information and knowledge. Beyond that, it also enables the exchange and combination of resources far beyond the firm's precincts. In this regard, it is a managerial input to initiate social capital, to develop and maintain it, allowing the firm to leverage it as it surges forward with its corporate aims and objectives (Wolf, Webb and Schweikert, 2008).

From its role, nature, and formation, we conclude that social capital is a conduit where formal and informal organisational structure, formal and informal communication, formal and informal knowledge of a firm meet. This creates the much-needed oasis in an organisational entrepreneurship ecosystem.

The managerial cognition component of dynamic managerial capabilities is concerned with acquiring and processing of information into formidable decisions, and this process is influenced by the managers' background, 
beliefs, experience and knowledge (Colman, 2006). Managerial cognition among managers is complex to determine, largely because it can only manifest itself in the actions and behaviour of managers. A set of skills has been suggested to point to managerial cognition. These include, problem solving, analysis, synthesising and comprehension of issues (Taylor, 2005). The construct by nature is a psychological domain issue. Until we get contribution from the psychologists on how to measure it, its determination will only be limited to the demographic factors such as age, qualifications, socio-economic background and gender as shown by the prevailing literature by Tyler and Steensma,(1988), Helfat \& Martin, (2015), Dong (2016), and most recently Correa, Bueno \& Kato, (2017).

Dong (2016) presented managerial cognition as the force behind effective coordination and combination of firm resources. Using managers from 921 American manufacturing firms, Dong (2016) concluded that managers who displayed high managerial cognition levels, performed well in inspiring novel processes, and they managed their resources better than those with weak cognition levels. The determination of managerial cognition by Dong (2016) was, however, based on the traditional demographic factors and did not include psychological cognitive issues. There is a consensus among management and organisational scholars that managerial cognition accounts for strong distinct strategic outcomes, and it promotes novel approaches to mitigate the changing business environment. This places managerial cognition as a possible influencer of organisation entrepreneurship. Such a consideration seems to have escaped scholarly attention.

Prevailing literature confirms that dynamic managerial capabilities promote strategic reorientation, resources combination, deployment and resources configuration. These activities are essential in promoting organisational adaptation, survival and growth, and they resonate well with the nature, scope and outcomes of organisational entrepreneurship.

\section{Conceptualisation of Corporate Entrepreneurship}

Referred to in some circles as Organisational Entrepreneurship (Dhliwayo, 2010), an entrepreneurial organisation has the dedication and desire to take advantage of new opportunities, undertake responsibility to create innovative and effective change, as well as strategic renewal (Morris and Kuratko, 2002, Dess and Lumpkin, 2005). All firms are from entrepreneurial activities by founding members (Covin and Miles, 2007). This causes entrepreneurship to be commonly associated with new ventures, small businesses or individuals (Covin and Miles, 2007). CE is an institutional concept within an established organisation (Ginsbery and Hay, 1994). It is concerned with the entrepreneurial behaviour of an organisation, regardless of its age or size. It looks at collective entrepreneurial behaviour of organisational members that keeps the organisation rejuvenated and energised to deal with dynamic environment, and in the process it acquires the ability to transform itself into superior organisational performance (Morris, Kuratko \& Cavin, 2011). Such behaviour becomes part of organisational culture and is either formal or informal in nature (Zahra, 1991).

Innovativeness is proactive and undertakes risky business, some of the characteristics of CE (Morris et.al, 2011). Innovation is central to the entrepreneurial ecosystem (Hisrich, 2008). An innovative organisation is very creative and promotes research and development in the quest for new products and operational processes. This leads to competitive advantage (Covin and Miles, 2008). Proactive organisations hedge themselves against market tremors. They develop new products and processes in anticipation of market changes, making themselves future proof (Zanra, 1991). Risk-taking in terms of undertaking novel projects by entering new markets, is synonymous with an organisation whose entrepreneurial levels are high. Despite these advantages about CE, it has documented challenges. Hisrich (2008) pointed out that the coordination of the CE process, is its fundamental challenge. New ventures formed within an organisation were found to be of inferior performance, compared to the ones founded by individuals outside organisations (Hisrich, 2008).

Several conceptual models that attempt to present the nature and scope of CE emerge in entrepreneurship literature: the Domain model of Corporate Entrepreneurship (Guth and Ginberg, 1990), an Interactive Model of Corporate Entrepreneurship (Hornsby, Naffziger, Kuratko, and Montagno, 1993) and a Model of Sustained Corporate Entrepreneurship (Kuratko, Morris, and Covin, 2011).

The Domain model of Corporate Entrepreneurship (Guth and Ginberg, 1990) identifies external variables such as technology, industrial life cycle and competition as control variables that give the context of organisational entrepreneurial behaviour. The internal variables that include top management philosophy and values, organisational structure, organisational culture, and organisational resources, are key constructs in influencing CE. The Interactive Model of Entrepreneurship (Hornsby, et al, 1993) presents the same constructs in the formation 
of CE as Guth and Ginberg (1990) - their focus is on the human agency. The model presents characteristics of individuals that feed the overall entrepreneurial behaviour of an organisation (Hornsby, et al, 1993). Echoing the role of individuals' entrepreneurship, the Model of Sustained Corporate Entrepreneurship (Kuratko et al, 2011) presents an organisation's internal environment as predictor variables in modelling employees' entrepreneurial perception. It is this perception that will sustain CE (Kuratko et al, 2011).

In bringing these models together, Hornsby, Kuratko, Holt and Wales (2013) presented the Corporate Entrepreneurship Climate Instrument (CECl). The use of $\mathrm{CECl}$ is to assist managers in their diagnoses of organisational entrepreneurship climate. The instrument identifies five antecedents of CE: organisational boundaries, discretionary time, rewards/ reinforcements, work discretion, and management support (Hornsby et al, 2013).

\section{Dynamic Managerial Capabilities as Antecedents of Corporate Entrepreneurship: A Conceptual Model}

To our knowledge and backed by prevailing literature, organisational boundaries, discretionary time, rewards/ reinforcements, work discretion, organisational culture, organisational structure and management support, are antecedents of CE. Drawing from management, organisational scholarship and practice, the paper submit that all these mentioned constructs as predictors of $\mathrm{CE}$, are a management function, hence, conceptualising dynamic managerial capabilities denoted by social capital, human capital, and managerial cognition as predicator variables in influencing CE. The relationship between dynamic managerial capabilities is mediated by organisational boundaries, discretionary time, rewards/reinforcements, work discretion, organisational culture, organisational structure.

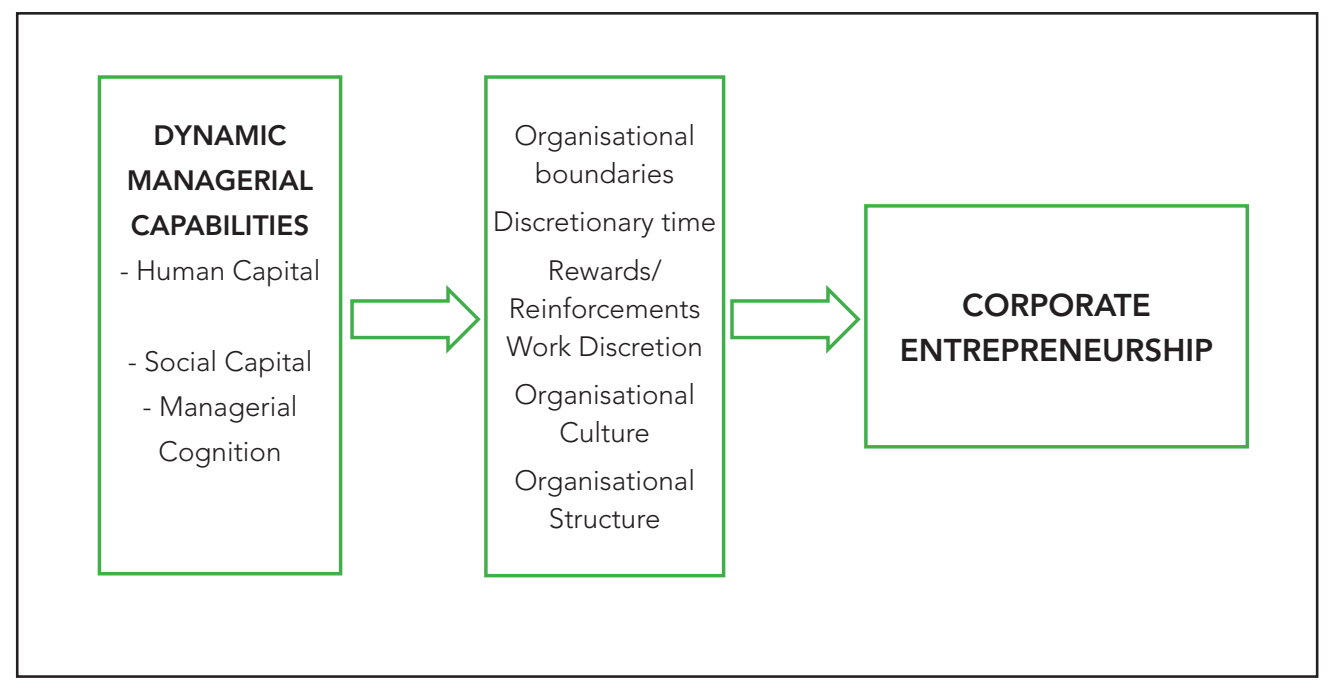

Fig 1: Dynamic Managerial Capabilities Corporate Entrepreneurship Model

Human capital development predicts CE through the mediating effects of organisational boundaries, discretionary time, rewards/reinforcements, work discretion and organisational structure. Through effective management of human capital, talent synergies are established, teamwork is consolidated, and employee autonomy is achieved. Organisational boundaries in organisations with a well-developed human capital are easy to define, palatable and allow organisations to adapt to changing environments. Autonomous employees use their discretion in performing tasks. This promotes the much-needed innovation in the CE formation process. Human capital development influences organisational culture and structure that cumulates in the promotion of CE.

Social capital is a precursor of CE through the mediating effects of organisational boundaries, culture, structure, discretionary time, rewards/reinforcements and work discretion. The value created by social connections in an organisation has direct influence on organisational structure and culture. It defines organisational boundaries. Furthermore, it influences employees' discretion to perform tasks. This creates a conducive environment for CE to develop.

Managerial cognition is an antecedent of CE through the mediating effects of organisational boundaries, discretionary time, rewards/reinforcements, work discretion, organisational structure and culture. A manager's cognitive ability influences organisation boundaries, organisational culture, organisational structure and employees' discretion. 


\section{Implications for Theory and Practice}

Drawing from literature and practice, we contribute to the creation of CE by presenting a novel conceptual model that considers dynamic managerial capabilities as antecedents of $C E$ through the mediating effects of organisational boundaries, culture, structure, discretionary time, rewards/reinforcements and work discretion. Prevailing literature places organisational boundaries, culture, structure, discretionary time, rewards/reinforcements, and work discretion as predictors of CE. We submit that these variables are an act of a managerial function, hence, our conceptualisation of dynamic managerial capabilities as predicator variables of CE through the mediating effects of organisational boundaries, culture, structure, discretionary time, rewards/reinforcements and work discretion.

One of the documented challenges of CE is the high failure rate of new ventures in organisations (Hisrich, 2008). This prevalent failure of new ventures is attributed to CE management quandaries such as entrepreneurial coordination challenges. By including social capital in our model, we suggest a mitigating strategy to this predicament. Social capital is a duct where formal and informal organisational structure, formal and informal communication, formal and informal knowledge of a firm, converge. Through social capital leveraging, managers are able to coordinate the CE process.

\section{Conclusion, limitations and indication for further research}

We conceptualised organisational capabilities in general and dynamic managerial capabilities in particular. Prevailing literature on the characteristics, scope and nature of CE were considered prior to presenting the Dynamic Managerial Capabilities Corporate Entrepreneurship Model, which considered dynamic managerial capabilities as the antecedents of CE. The model makes the following propositions.

1. Human capital development predicts CE through the mediating effects of organisational boundaries, discretionary time, rewards/reinforcements, work discretion and organisational structure.

2. Social capital is a precursor of CE through the mediating effects of organisational boundaries, culture, structure, discretionary time, rewards/reinforcements and work discretion.

3. Managerial cognition is a predictor variable of CE through the mediating effects of organisational boundaries, discretionary time, rewards/reinforcements, work discretion, organisational structure and culture.

4. In combination, human capital, social capital and managerial cognition are the antecedents of CE through the mediating effects of organisational boundaries, discretionary time, rewards/reinforcements, work discretion and organisational structure.

The model is conceptual; an empirical study of CE is likely to reveal more insights into the relationship between dynamic managerial capabilities and CE.

\section{References}

Adner, R, \& Helfat, C. E. (2003). Corporate effects and dynamic managerial capabilities. Strategic Management Journal, 24(10), 1011-1025

Agarwal, R. , \& Selen, W. (2009). Dynamic capability building in service value networks for achieving service innovation, Decision Sciences, 40 (3), 431-475.

Ambrosini, V. , \& Bowman,C. (2009). What are dynamic capabilities and are they a useful construct in strategic management? International Journal of Management Reviews, 11(1), 29-49.

Ambrosini,V. , Bowman, C \& Collier, N. (2009). Dynamic capabilities: An exploration of how firms renew their resources base. British Journal of Management, 2 (1),9-24.

Andersson, S. , \& Evers, N. (2015). International opportunity recognition in international new ventures: A dynamic managerial capabilities perspective. Journal of International Entrepreneurship, 13(3), 260-276.

Blyler, M. , \& Coff, R. W. (2003). Dynamic capabilities, social capital, and rent appropriation: Ties that split pies. Strategic Management Journal, 24, 677-686

Bowman, C. , \& Ambrosini, V. (2003). How the resource-based and the dynamic capability views of the firm inform corporate-level strategy. British Journal of Management, 14, 289-303.

Burt, S. R., (2005). Brokerage and closure: An introduction to social capital. Editora: Oxford University. 
Castanias, R. P. , \& Helfat, C. E. (1991). Managerial resources and rents. Journal of Management, 17(1), 155-171.

Chandler, AD. (1977). The Visible Hand: The Managerial Revolution in American Business, Cambridge, Harvard University Press.

Chandler, AD. (1992). Organisational capabilities and economic history of the industrial enterprise, The Journal of Economic Perspectives. 6 (3),79-100.

Colman, A. M. (2006). A dictionary of psychology. Oxford, UK: Oxford University Press.

Corrêa RO. , Bueno EV \& Kato HT, (2019). Dynamic managerial capabilities: Scale development and validation. Management Decisions Economics. 40:3-15

Covin, J.G. , \& Miles, M.P. (2007). Corporate entrepreneurship and the pursuit of competitive advantage. Entrepreneurship Theory and Practice, 23(3): 47 - 64.

Danneels, E.(2012). Trying to become a different type of a company: Dynamic capability at Smith Corona. Strategic Management Journal, 32, 1-31.

Dess, G. , and Lumpkin, G.T. 2005. Research Edge: The role of entrepreneurial orientation in stimulating effective corporate entrepreneurship. The Academy of Management Executive, 19(1): 147 - 156.

Dhliwayo, S. (2010). The entrepreneurial organisation. In the frontiers in Entrepreneurship: 139-158. Edited by Urban, B. Springer: Berlin.

Dong, J. Q. (2016). On the contingent rent-generating potential of firm specific managerial experience. Journal of Business Research, 69(10), 4358-4362.

Eisenhardt, K. M. , \& Martin, J. A. (2000). Dynamic capabilities: What are they? Strategic Management Journal, 21, 1105-1122.

Ginsberg, A. , and Hay, M. (1994). Confronting the challenges of corporate entrepreneurship: Guidelines for venture managers. European Management Journal, 12(4): 382 - 389.

Gottschalg,O., \& Zollo,M. (2007). Interest alignment and competitive advantage. Academy of Management Review, 32(2), 418-437.

Guth, W.D. , \& Ginsburg, A. (1990). Guest editor's introduction: Corporate entrepreneurship Strategic Management Journal, 11:5- 25 .

Helfat, C. E. , \& Martin, J. A. (2015). Dynamic managerial capabilities: Review and assessment of managerial impact on strategic change. Journal of Management, 41(5), 1281-1312.

Hisrich, R.D. , \& Peters, M.P. (1992). Entrepreneurship: Starting, Developing, and Managing a New Enterprise, 7th Ed. Home word, IL, Irwin Print

Hisrich, R.D. , Peters, M.P., \& Shepherd, D.L. (2008). Entrepreneurship, 7th ed. New York: McGraw-Hill.

Hornsby, J.S. , Kuratko, D.F. , Holt, D.T. , \& Wales, W.J. (2013). Assessing a measurement of organisational preparedness for corporate entrepreneurship. Journal of Product Innovation Management, 30(5): 937 - 955.

Hornsby, J. , Naffziger, D.W. , Kuratko, D.F. , \& Montagno, R.V (1993). An interactive model of the corporate entrepreneurship process. Entrepreneurship Theory and Practice, 3:29 - 37.

Liu,X. , Grant, B.D. , McKinnon, A.C \& Feng,Y. (2010). An empirical examination of the contribution of capabilities to the competitiveness of logistics services providers: A perspective from China. International Journal of Physical Distribution and Logistics and Management, 40(10),847-866.

Kogut, B. ,\& Zander, U. (1992). Knowledge of the firm, combinative capabilities and the replication of technology. Organisation Science, 3(3),383-397.

Morris, M.H. , and Kuratko, D.F. (2002). Corporate Entrepreneurship: Entrepreneurial Development within organisations. Quorum Book, Westport

Morris, M.H. , Kuratko, D.F., and Covin, J. (2011). Corporate Entrepreneurship and Innovation. 3rd ed. Mason, OH: South-Western Cengage.

Nelson, R, R. , and Winter, S. (2009). An evolutionary theory of a firm , $4^{\text {th }}$ ed. Cambridge: Belknap Harvard University Press.

Pavlou,P.A., \& El Sawy,O.A. (2011). Understanding the elusive black box of dynamic capabilities, Decision Sciences, 
$42(1), 239-273$.

Putnam, R. D. (2000). Bowling alone: The collapse and revival of American community. New York: Simon and Schuster.

Rosenbloom, R. S. (2000). Leadership, capabilities, and technological change: The transformation of NCR in the electronic era. Strategic Management Journal, 21(10-11), 1083-1103

Selznick,P. (1957). Leadership in administration: A sociological interpretation. New York: Harper and Row

Schienstock,G.(2009). Organisational capabilities: Some reflections on the concept. IAREG-Intangible Assets and Regional Economic Growth, 1(2),39-53.

Sirmon, D. G. , \& Hitt, M. A. (2009). Contingencies within dynamic managerial capabilities: Interdependent effects of resource investment and deployment of firm performance. Strategic Management Journal, 30(13), 1375-1394.

Taylor, L. (2005). Introducing cognitive development. East Sussex: Psychology Press.

Tyler, B. B. , \& Steensma, H. K. (1998). The effects of executives' experiences and perceptions on their assessment of potential technological alliances. Strategic Management Journal, 19(10), 939-965.

Ulrich, D. \& Lake, D. (1991). Organisational capability: creating competitive advantage. The Executive, 5 (1), 77-92.

Winter, S.G. (1987). Action research and the nature of social inquiry: Professional innovation and educational work. Hampshire: Ashgate Publishing Company.

Winter, SG. (2000). The satisficing principle in capability learning. Strategic Management Journal, 21(10-11), $981-$ 996.

Winter, SG. (2003). Understanding dynamic capabilities. Strategic Management Journal, 24(10),991- 995.

Winter, S. G. (2005). Developing Evolutionary Theory for Economics and Management. In M. Hittand K. G. Smith (Eds.), Oxford Handbook of Management Theory: Oxford: Oxford University Press.

Winter, S.G. (2013). Habit, deliberation, and action: Strengthening the micro foundations of routines and capabilities. The Academy of Management Perspectives, 27 (2),120-137.

Wolf, P., Webb, C. , \& Schweikert, S. (2008). Using agile project management for managing regional innovation projects: How does complex adaptive systems thinking influence a manager? In 9th International CINet (Continuous Innovation Network) Conference, Radical Challenges in Innovation Management, pp. 5-9. Valencia, Spain.

Wright, P. M. , Coff, R., \& Moliterno, T. P. (2014). Strategic human capital: Crossing the great divide. Journal of Management, 40, 353-370.

Zahra, S.A. (1991). Predictors and financial outcomes of corporate entrepreneurship. An exploratory study. Journal of Business Venturing, 6:259 - 285.

Zollo, M. , \& Winter, S. G. (2002). Deliberate learning and the evolution of dynamic capabilities. Organization Science, 13(3), 339-351. 